\title{
Relationship between total vitamin D metabolites and complications in patients with type 2 diabetes
}

\author{
LINA H.M. AHMED ${ }^{1}$, ALEXANDRA E. BUTLER ${ }^{2}$, SOHA R. DARGHAM ${ }^{1}$, AISHAH LATIF $^{3}$, \\ ELHADI A. AHMED ${ }^{4}$, ABUBAKER HASSAN $^{4}$ and STEPHEN L. ATKIN ${ }^{5}$
}

\author{
${ }^{1}$ Research Department, Weill Cornell Medicine-Qatar, P.O. Box 24144, Doha; ${ }^{2}$ Diabetes Research Center, \\ Qatar Biomedical Research Institute, Hamad Bin Khalifa University, Qatar Foundation, P.O. Box 34110, Doha; \\ ${ }^{3}$ Antidoping Laboratory Qatar, P.O. Box 27775, Doha, Qatar; ${ }^{4}$ Faculty of Medical Laboratory Sciences, University of \\ Gezira, P.O. Box 20, Wad Medani, Sudan; ${ }^{5}$ Royal College of Surgeons in Ireland, P.O. Box 15503, Manama, Bahrain
}

Received July 14, 2020; Accepted October 30, 2020

DOI: 10.3892/br.2020.1394

\begin{abstract}
In our previous study, it was shown that endogenous vitamin $\mathrm{D}_{3}$ and its metabolites are associated with diabetic microvascular complications and cardiovascular risk factors. The aim of the present study was to determine if the relationship between total vitamin $\mathrm{D}$ (vitamin $\mathrm{D}_{2}$ supplements plus endogenous vitamin $\mathrm{D}_{3}$ ) was a better predictor of complications in type 2 diabetes (T2DM). A total of 460 patients with T2DM participated in the present cross-sectional study. Plasma levels of total vitamin D and its metabolites (1,25-dihydroxyvitamin D (1,25(OH)D), 25-hydroxyvitamin D $(25(\mathrm{OH}) \mathrm{D})$ and 24,25-dihydroxyvitamin D $(24,25(\mathrm{OH}) \mathrm{D})$ were measured by isotope-dilution liquid chromatography tandem mass spectrometry analysis. 1,25-dihydroxyvitamin $\mathrm{D}_{3}$ and 25-hydroxyvitamin $\mathrm{D}_{3}$ were associated with diabetic retinopathy and coronary artery disease, but total 1,25-dihydroxyvitamin D and total 25-hydroxyvitamin D levels were not statistically associated with any complications. Total 1,25-dihydroxyvitamin $\mathrm{D}$ showed the same positive association as 1,25 -dihydroxyvitamin $\mathrm{D}_{3}$ for hypertension and dyslipidemia, and total 25-hydroxyvitamin D showed the same positive association as 25 -hydroxyvitamin $\mathrm{D}_{3}$ for dyslipidemia. Total 24,25-dihydroxyvitamin $\mathrm{D}$ showed the same positive association only with dyslipidemia as did 24,25-dihydroxyvitamin $\mathrm{D}_{3}$. However, total 25-hydroxyvitamin D was associated with hypertension, whereas 25-hydroxyvitamin $\mathrm{D}_{3}$ was not Vitamin $\mathrm{D}_{3}$ metabolites were associated with diabetic retinopathy, whereas total vitamin D levels were not, suggesting that endogenous vitamin $\mathrm{D}_{3}$ metabolites are a better measure of diabetic microvascular complications. However, both total
\end{abstract}

Correspondence to: Professor Alexandra E. Butler, Diabetes Research Center, Qatar Biomedical Research Institute, Hamad Bin Khalifa University, Qatar Foundation, P.O. Box 34110, Doha, Qatar E-mail: aeb91011@gmail.com

Key words: vitamin D deficiency, vitamin D, vitamin D3, vitamin metabolites, type 2 diabetes, diabetes complications vitamin $\mathrm{D}$ and vitamin $\mathrm{D}_{3}$ metabolites were associated with cardiovascular risk factors in patients with type 2 diabetes.

\section{Introduction}

Vitamin D deficiency may increase the risk of development of type 2 diabetes (T2DM) (1-3), given its inverse relationship with diabetes onset (4). Both insulin resistance and $b$ cell dysfunction are associated with vitamin D deficiency (5), and obesity can exacerbate vitamin D deficiency through sequestering of vitamin D into adipose tissue (6). Vitamin D deficiency in T2DM has also been associated with microvascular complications, although causality remains unclear (7).

Vitamin $\mathrm{D}_{3}$ (also known as cholecalciferol) is produced endogenously in the body, whereas vitamin $\mathrm{D}_{2}$ is ingested in the diet as ergosterol, with mushrooms and fungi being the primary sources, and is then converted to ergocalciferol by ultraviolet light; multiple 25 -hydroxylases then convert the ergosterol and cholecalciferol to vitamin $\mathrm{D}_{2}\left(25(\mathrm{OH}) \mathrm{D}_{2}\right)$ and vitamin $\mathrm{D}_{3}\left(25(\mathrm{OH}) \mathrm{D}_{3}\right)$, respectively $(8,9)$. In the kidney, vitamin $\mathrm{D}$ is converted to the active $1,25(\mathrm{OH})_{2} \mathrm{D}$ form by 1a-hydroxylase, or to $24,25(\mathrm{OH})_{2} \mathrm{D}$ (10) (Fig. 1); 1,25(OH) ${ }_{2} \mathrm{D}$ is produced in extrarenal tissues and may, and act locally (10).

Vitamin $\mathrm{D}_{2}$ is readily available as an oral supplement to counter vitamin D deficiency, and is often preferentially used over vitamin $\mathrm{D}_{3}$ as the latter is more costly; therefore, the vitamin D levels and its metabolites assayed and reported may be a composite of vitamin $\mathrm{D}_{2}$ and vitamin $\mathrm{D}_{3}$, as assays may not distinguish between them (11).

In our previously study, the association between of vitamin $\mathrm{D}_{3}$ deficiency and microvascular or cardiovascular risk complications in patients with T2DM was reported (12). Therefore, the aim of the present study was to determine if total vitamin $\mathrm{D}$ was a better predictor of complications in T2DM than vitamin $\mathrm{D}_{3}$ alone.

\section{Patients and methods}

Study population. A total of 460 patients with T2DM (median age 55.2 years; age range, 30-90 years; 227 male and 233 female) were recruited from patients attending the Hamad 
General Hospital diabetes clinic, Qatar, between July 2013 and July 2015 (Table I). The criteria for inclusion in the study were: Qatari ethnicity and $\geq 30$ years old. T2DM was diagnosed based on the World Health Organization guidelines (13). For inclusion in the T2DM cohort, one or more of the following criteria had to be met: Fasting plasma glucose of $>7 \mathrm{mmol} / \mathrm{l}$, HbA1c $>6.5 \%$ or a diagnostic glucose tolerance test. All diabetic patients had an estimated glomerular filtration rate of $>60 \mathrm{ml} / \mathrm{min} / \mathrm{kg}$ to ensure that vitamin D levels were not confounded by renal dysfunction. A total of 290 control subjects were included in the present study (median age 46.1 years; age range, 30-85 years; 151 male and 139 female). To be included in the nondiabetic control group, a normal glucose tolerance test was required. Criteria for exclusion were type 1 diabetes, gestational diabetes or secondary diabetes due to steroid treatment. The T2DM subjects underwent retinal photography, foot examination and measurement of blood pressure.

All study subjects had received vitamin $\mathrm{D}_{2}$ supplements, 50,000 units weekly, prescribed for at least the preceding 4 months. Diabetes subjects were all treated with at least 2 antidiabetic medications that included metformin, and whilst patients were prescribed insulin, compliance could not be confirmed.

This study was approved by Weill Cornell Institutional Review Board (approval no. IRB\# 13-00063); all study subjects provided written informed consent. Trial conduct was undertaken in accordance with the International Conference on Harmonisation-Good Clinical Practice (ICH GCP) and the Declaration of Helsinki (14).

Study design. The study design has been previously described (15). Briefly, patients were fasted overnight, and subsequently, blood samples were collected, as well as the baseline weight and blood pressure. Fasting venous blood was collected in fluoride oxalate and serum gel tubes (BD Diagnostics; Becton, Dickinson and Company). The samples were separated by centrifugation at $2,000 \times \mathrm{g}$ for $15 \mathrm{~min}$ at $4^{\circ} \mathrm{C}$, and within $1 \mathrm{~h}$ of collection, the aliquots were stored at $-80^{\circ} \mathrm{C}$. Overnight urine samples were also collected, aliquoted and stored at $-80^{\circ} \mathrm{C}$, and analyzed in batches. Blood pressure was measured using an automated device (NPB-3900; Nellcor Puritan Bennett) during each visit. Blood pressure measurements were performed after the subjects had been seated quietly for at least $5 \mathrm{~min}$, using the right arm which was supported at heart level. For each measurement, three readings were taken, at least 2 min intervals, and the mean of the three readings was recorded (15).

Diabetic retinopathy was diagnosed using fundoscopy and diabetic neuropathy was diagnosed based on the vibration perception threshold (Neurothesiometer NU-1, Horwell-UK) of the great toe being $>25 \mathrm{~V}$ (16).

Coronary artery disease (CAD) was defined as a history of myocardial infarction or angina, confirmed by coronary angiography (17). Peripheral arterial disease (PAD) was defined as a history of claudication or pain at rest with evidence of artery stenosis on ultrasound or lower limb angiography (18). Stroke was defined as a sudden onset neurological deficit lasting $>24$ h (19).

Serum vitamin D levels were measured using isotopedilution liquid chromatography tandem mass spectrometry (LC-MS/MS) as described previously (12).
Statistical analysis. Statistical analysis was performed as described previously (20). The sample size used in the present study was based on a previous study, which found that $51 \%$ of diabetics without microvascular complications and $80 \%$ with retinopathy exhibited vitamin D deficiency (7). Using the $49 \%$ of patients without retinopathy as the comparison group, a sample size of 274 diabetic patients was selected, which provides $80 \%$ statistical power to detect a $68 \%$ prevalence of vitamin D deficiency in the retinopathy group. When examining the mean differences in vitamin D, the 460 patients, assuming $40 \%$ $(n=184)$ have retinopathy, this would yield an harmonic mean of the sample size of $\sim 132$. Using this sample size provided $95 \%$ power for a difference in vitamin $\mathrm{D}$ means of 0.35 deviations using a t-test, which was considered a moderate-sized effect.

Data trends were visually and statistically evaluated for normality. Non-parametric tests (Mann Whitney U) were used on data that violated the assumptions of normality when tested using a Kolmogorov-Smirnov Test (20). Statistical analysis was performed using SPSS version 24.0. Values are reported as the median (inter-quartile range).

\section{Results}

Baseline characteristics. The baseline characteristics for the T2DM and the control cohorts are shown in Table I. The diabetic patients were significantly older $(\mathrm{P}<0.001)$ and had a higher BMI $(\mathrm{P}<0.001)$ compared to the control subjects. The diabetic patients also had elevated HbAlc $(\mathrm{P}<0.001)$ and fasting glucose levels compared with the control group $(\mathrm{P}<0.001)$.

Vitamin D measurements. The levels of total $25(\mathrm{OH}) \mathrm{D}$ were significantly higher compared with the $25(\mathrm{OH}) \mathrm{D}_{3}(\mathrm{P}<0.001)$. The levels of total $1,25(\mathrm{OH})_{2} \mathrm{D}$ and total $24,25(\mathrm{OH})_{2} \mathrm{D}$ did not differ compared with the levels of $1,25(\mathrm{OH})_{2} \mathrm{D}_{3}$ and $24,25(\mathrm{OH})_{2} \mathrm{D}_{3}(\mathrm{P}>0.05)$.

The lower active total $1,25(\mathrm{OH})_{2} \mathrm{D}$ levels were associated with hypertension and dyslipidemia in diabetic patients $(\mathrm{P}=0.03)$ in comparison with the lower $1,25(\mathrm{OH})_{2} \mathrm{D}_{3}$ levels, which were associated with diabetic retinopathy $(\mathrm{P}=0.006)$ hypertension and dyslipidemia (both $\mathrm{P}=0.01)$ as well as $\mathrm{CAD}(\mathrm{P}=0.012)$. There was no association between either total $1,25(\mathrm{OH})_{2} \mathrm{D}$ or $1,25(\mathrm{OH})_{2} \mathrm{D}_{3}$ levels with diabetic neuropathy, PAD or CAD. Total $25(\mathrm{OH}) \mathrm{D}$ levels were associated with both hypertension and dyslipidemia $(\mathrm{P}<0.001)$ in comparison with $25(\mathrm{OH}) \mathrm{D}_{3}$ levels, which were associated with diabetic retinopathy $(\mathrm{P}=0.03)$ and dyslipidemia $(\mathrm{P}=0.04)$. There was no association between either total $25(\mathrm{OH}) \mathrm{D}$ or $25(\mathrm{OH}) \mathrm{D}_{3}$ levels with diabetic neuropathy, dyslipidemia, PAD, CAD or stroke. Total $24,25(\mathrm{OH})_{2} \mathrm{D}$ levels were associated with dyslipidemia $(\mathrm{P}=0.03)$ in accordance with $24,25(\mathrm{OH})_{2} \mathrm{D}_{3}$ levels $(\mathrm{P}<0.02)$. There was no association between either total $24,25(\mathrm{OH})_{2} \mathrm{D}$ or $24,25(\mathrm{OH})_{2} \mathrm{D}_{3}$ with diabetic neuropathy, diabetic retinopathy, hypertension, PAD, CAD or stroke. None of the vitamin D metabolites were associated with diabetic neuropathy or stroke (Table II).

Total 25(OH)D levels were significantly higher compared with $25(\mathrm{OH}) \mathrm{D}_{3}(\mathrm{P}<0.001)$, but those of $1,25(\mathrm{OH})_{2} \mathrm{D}$ and $24,25(\mathrm{OH})_{2} \mathrm{D}$ did not differ between total and $\mathrm{D}_{3}$ metabolites. When the subjects with $25(\mathrm{OH}) \mathrm{D}$ deficiency $(\leq 20 \mathrm{ng} / \mathrm{ml})$ were compared to those who were replete $(\geq 30 \mathrm{ng} / \mathrm{ml})$, there was no difference in hypertension, dyslipidemia, retinopathy 
Table I. Clinicopathological characteristics, vitamin D levels and metabolite levels in the Control and Type 2 Diabetic cohorts.

\begin{tabular}{lccc}
\hline Parameter & Control $^{\mathrm{c}}$ & Diabetes $^{\mathrm{c}}$ & P-value \\
\hline Age, years & $46(30.0-85)$ & $55(30-90)$ & $<0.001^{\mathrm{b}}$ \\
BMI, kg/m & $30.1(21.7-53.5)$ & $32.4(17.0-61.0)$ & $<0.001^{\mathrm{b}}$ \\
HbAlc, $\%$ & $5.6(4.4-9.0)$ & $7.9(4.9-15.9)$ & $<0.001^{\mathrm{b}}$ \\
Glucose, mmol/l & $5.2(2.9-11.1)$ & $8.6(2.3-29.0)$ & $<0.001^{\mathrm{b}}$ \\
Total 1,25(OH) $)_{2} \mathrm{D}, \mathrm{ng} / \mathrm{dl}$ & $0.044(0.000-2.087)$ & $0.02(0.000-0.189)$ & $<0.001^{\mathrm{b}}$ \\
Total 25(OH)D, ng/dl & $19.58(4.41-63.73)$ & $26.46(0.00-61.21)$ & $<0.001^{\mathrm{b}}$ \\
Total 24,25(OH)D, ng/dl & $0.387(0.000-4.486)$ & $0.290(0.000-7.772)$ & $<0.001^{\mathrm{b}}$ \\
Total 3epi25(OH)D , ng/dl & $0.206(0.000-7.564)$ & $0.326(0.000-4.001)$ & $0.005^{\mathrm{a}}$
\end{tabular}

${ }^{\mathrm{a}} \mathrm{P}<0.01,{ }^{\mathrm{b}} \mathrm{P}<0.001 .{ }^{\mathrm{c}} \mathrm{Median}$ (range).

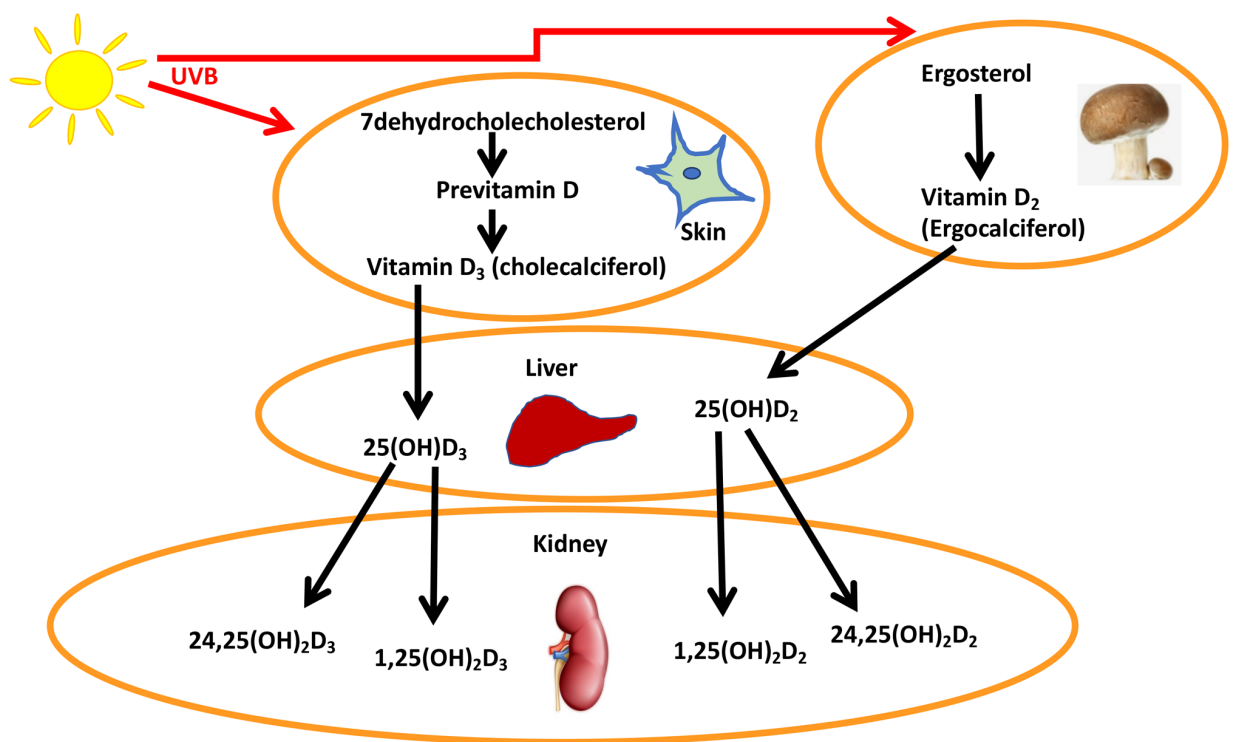

Figure 1. Vitamin D pathways. In the skin, 7-dehydrocholesterol is converted to pre-vitamin D3 and then to vitamin $\mathrm{D}_{3}$. This is transported to the liver via DBP, which also transports $25(\mathrm{OH}) \mathrm{D}_{3}$ to the kidney. In the kidney, $25(\mathrm{OH}) \mathrm{D}_{3}$ is taken up by tubular cells and undergoes conversion to the active $1,25(\mathrm{OH})_{2} \mathrm{D}_{3}$ and $24,25(\mathrm{OH})_{2} \mathrm{D}_{3}$. Vitamin $\mathrm{D}_{2}$ comes from the diet (yeasts and fungi) and is converted to $25(\mathrm{OH}) \mathrm{D}_{2}$ in the liver and to $1,25(\mathrm{OH})_{2} \mathrm{D}_{2}$ and $24,25(\mathrm{OH})_{2} \mathrm{D}_{2}$ in the kidney. DBP, vitamin D binding protein $25(\mathrm{OH}) \mathrm{D}_{3}, 25$ hydroxy vitamin $\mathrm{D}$.

or neuropathy (data not shown). There was no correlation between the estimated glomerular filtration rate and any of the vitamin D metabolites (data not shown).

\section{Discussion}

Total 25(OH)D levels were significantly higher compared with those of $25(\mathrm{OH}) \mathrm{D}_{3}$, and this reflects the vitamin $\mathrm{D}_{2}$ supplementation that these patients were taking. However, the levels of total $1,25(\mathrm{OH})_{2} \mathrm{D}$ and total $24,25(\mathrm{OH})_{2} \mathrm{D}$ did not differ to those of $1,25(\mathrm{OH})_{2} \mathrm{D}_{3}$ and $24,25(\mathrm{OH})_{2} \mathrm{D}_{3}$. This result is in agreement with a study on high dose vitamin $\mathrm{D}_{2}$ supplementation, which showed that vitamin $\mathrm{D}_{2}$ was less efficacious at raising serum $25(\mathrm{OH}) \mathrm{D}$ levels than vitamin $\mathrm{D}_{3}$, and that vitamin $\mathrm{D}_{2}$ did not increase the $1,25(\mathrm{OH})_{2} \mathrm{D}$ levels to the same degree that vitamin $\mathrm{D}_{3}$ supplementation did (21). This also supports the notion that vitamin $\mathrm{D}_{3}$ is better than vitamin $\mathrm{D}_{2}$ for treating vitamin $\mathrm{D}$ deficiency (21), and that vitamin $\mathrm{D}_{2}$ supplements may not sufficiently increase the levels of active $1,25(\mathrm{OH})_{2} \mathrm{D}$.
Both $25(\mathrm{OH}) \mathrm{D}_{3}$ and $1,25(\mathrm{OH})_{2} \mathrm{D}_{3}$ were associated with diabetic retinopathy, whereas neither total $25(\mathrm{OH}) \mathrm{D}$ nor total $1,25(\mathrm{OH})_{2} \mathrm{D}$ levels were associated with diabetic retinopathy. It has been reported that in type 2 diabetes, vitamin $\mathrm{D}$ deficiency is associated with development of microvascular complications (22) and a recent meta-analysis highlighted an association between vitamin D deficiency and retinopathy (23); however, these outcomes were not specifically correlated to either total vitamin $\mathrm{D}$ or the vitamin $\mathrm{D}_{3}$ forms. These data may also suggest why vitamin $\mathrm{D}$ and diabetes studies reported in the literature are conflicting on the relationship of complications and benefits of vitamin D supplementation if the effects of total vitamin $\mathrm{D}$ differs from that of vitamin $\mathrm{D}_{3}(24)$.

Total vitamin $\mathrm{D}$, in comparison with vitamin $\mathrm{D}_{3}$ metabolites, showed very similar associations with the other cardiovascular parameters, including dyslipidemia, hypertension, PAD and stroke. The only additional significant result was the association between $1,25(\mathrm{OH})_{2} \mathrm{D}_{3}$ and $\mathrm{CAD}$, that was not seen with total $1,25(\mathrm{OH})_{2} \mathrm{D}$. 


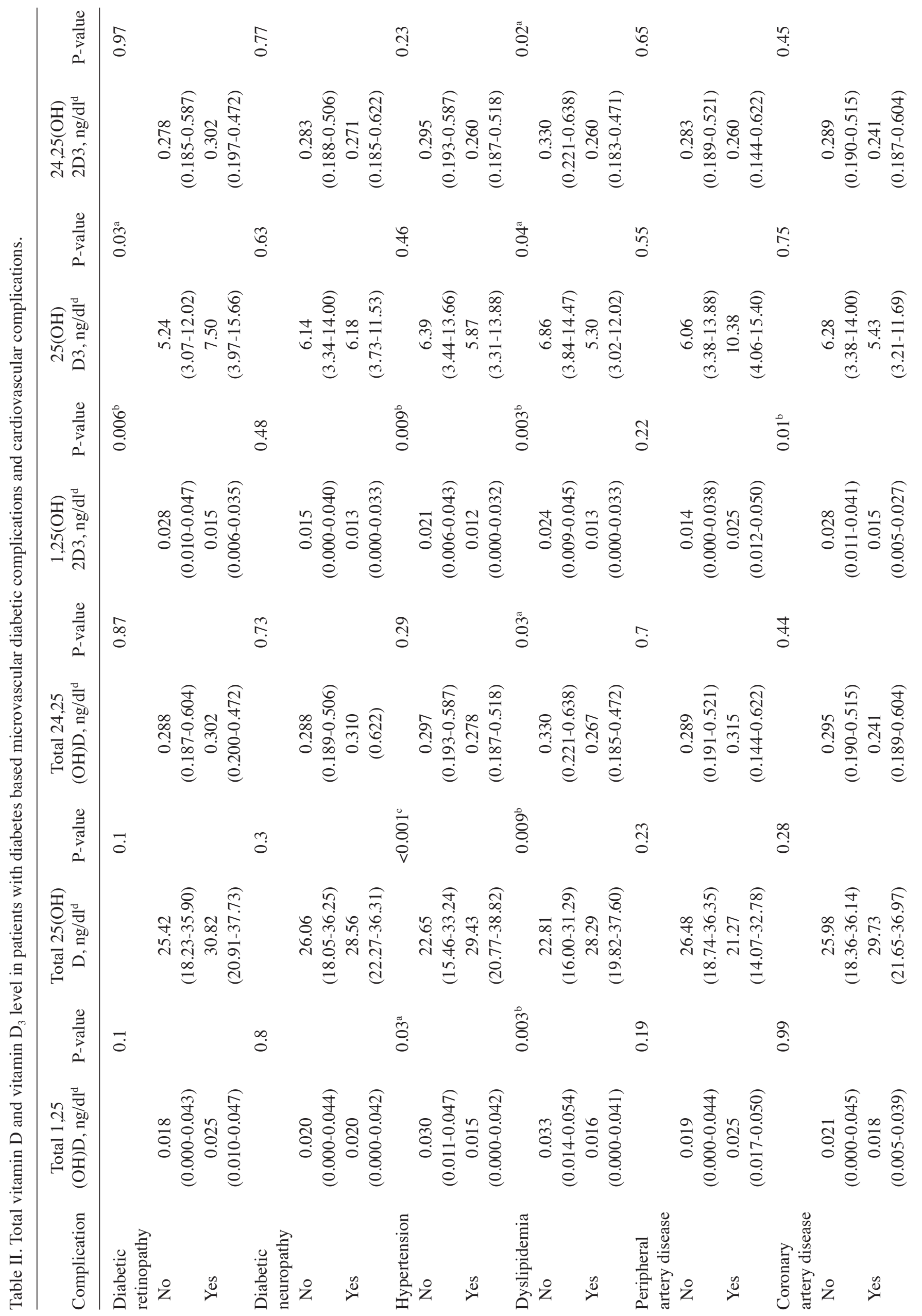


When the deficient and replete $25(\mathrm{OH}) \mathrm{D}$ populations were compared, there was no difference between them, suggesting that the serum 25(OH)D levels were not related to the development of hypertension or dyslipidemia. These changes were not a result of altered renal function, as there was no correlation with estimated glomerular filtration rate.

There is increasing evidence showing that vitamin D deficiency serves a role in the pathogenesis of type 2 diabetes (25-27) with evidence from epidemiological studies linking vitamin D deficiency and insulin resistance $(28,29)$. In adults at high risk of developing type 2 diabetes, supplementation with cholecalciferol has been shown to improve $b$ cell function (30) and $1,25(\mathrm{OH})_{2} \mathrm{D}$ may also improve insulin sensitivity by activating peroxisome proliferator-activated receptor $\delta$ (31). Conversely, long-term studies have found that vitamin D and calcium supplementation do not offer protection against the risk of diabetes development (22), and giving supplements to vitamin D replete patients with T2DM had no effect on insulin resistance or glycemic control (32); however, differing meta-analyses have shown an improvement in HbAlc in response to supplementation with vitamin D in some studies $(33,34)$, but not in others $(35)$.

Both the total $24,25(\mathrm{OH})_{2} \mathrm{D}$ and $24,25(\mathrm{OH})_{2} \mathrm{D}_{3}$ levels were significantly associated with dyslipidemia; $24,25(\mathrm{OH})_{2} \mathrm{D}$ may not be an inactive metabolite, as it has been shown to suppress Apo A-1 in hep G cells (36), and it may exhibit a physiological role in growth plate formation (8); therefore, a direct effect on lipid metabolism cannot be excluded.

The strength of the present cross-sectional study was the homogeneous Qatari population studied and the number of participants assessed using state-of-the-art measurements of 25(OH)D and metabolites, and these results may be generalizable to other Qatari populations. However, this study was limited by its cross-sectional design and that, whilst all subjects were prescribed vitamin $D_{2}$ supplements, it was not possible to ascertain compliance. Additionally, the results may not be generalizable to other ethnicities, for which a multi-center approach with participation from institutes in several different countries is required.

In conclusion, vitamin $\mathrm{D}_{3}$ metabolites were associated with diabetic retinopathy, whereas total vitamin $\mathrm{D}$ levels were not, suggesting that endogenous vitamin $\mathrm{D}_{3}$ metabolites are the better measure of diabetic microvascular complications. However, both total vitamin $\mathrm{D}$ and vitamin $\mathrm{D}_{3}$ metabolites were associated with cardiovascular risk factors in patients with type 2 diabetes.

\section{Acknowledgements}

Not applicable.

\section{Funding}

No funding was received.

\section{Availability of data and materials}

The datasets used and/or analyzed during the present study are available from the corresponding author on reasonable request. 


\section{Authors' contributions}

AEB analyzed and interpretated the data as well as wrote the manuscript. LHMA analyzed and interpretated the data. SRD performed the statistical analysis. AL performed the vitamin D measurements. EAA and $\mathrm{AH}$ participated in data analysis and interpretation, as well as prepared the manuscript. SLA designed the study and contributed to the discussion. All authors read and approved the final manuscript.

\section{Ethics approval and consent to participate}

This study was approved by Weill Cornell Institutional Review Board (approval no. IRB\# 13-00063). All study subjects provided written informed consent.

\section{Patient consent for publication}

Not applicable.

\section{Competing interests}

The authors declare that they have no competing interests.

\section{References}

1. Nakashima A, Yokoyama K, Yokoo T and Urashima M: Role of vitamin D in diabetes mellitus and chronic kidney disease. World J Diabetes 7: 89-100, 2016.

2. Husemoen LL, Thuesen BH, Fenger M, Jorgensen T, Glumer C Svensson J, Ovesen L, Witte DR and Linneberg A: Serum $25(\mathrm{OH}) \mathrm{D}$ and type 2 diabetes association in a general population: A prospective study. Diabetes Care 35: 1695-1700, 2012.

3. Mathieu C: Vitamin D and diabetes: Where do we stand? Diabetes Res Clin Pract 108: 201-209, 2015.

4. Pittas AG, Dawson-Hughes B, Li T, Van Dam RM, Willett WC Manson JE and Hu FB: Vitamin D and calcium intake in relation to type 2 diabetes in women. Diabetes Care 29: 650-656, 2006.

5. Chiu KC, Chu A, Go VL and Saad MF: Hypovitaminosis D is associated with insulin resistance and beta cell dysfunction. Am J Clin Nutr 79: 820-825, 2004.

6. Wortsman J, Matsuoka LY, Chen TC, Lu Z and Holick MF: Decreased bioavailability of vitamin D in obesity. Am J Clin Nutr 72: 690-693, 2000.

7. Bajaj S, Singh RP, Dwivedi NC, Singh K, Gupta A and Mathur M: Vitamin D levels and microvascular complications in type 2 diabetes. Indian J Endocrinol Metab 18: 537-541, 2014.

8. Bikle DD: Vitamin D metabolism, mechanism of action, and clinical applications. Chem Biol 21: 319-329, 2014.

9. Sakaki T, Kagawa N, Yamamoto K and Inouye K: Metabolism of vitamin D3 by cytochromes P450. Front Biosci 10: 119-134, 2005.

10. Christakos S, Dhawan P, Verstuyf A, Verlinden L and Carmeliet G: Vitamin D: Metabolism, molecular mechanism of action, and pleiotropic effects. Physiol Rev 96: 365-408, 2016.

11. Lhamo Y, Chugh PK and Tripathi CD: Vitamin D Supplements in the Indian Market. Indian J Pharm Sci 78: 41-47, 2016.

12. Butler AE, Dargham SR, Latif A, Mokhtar HR, Robay A, Chidiac OM, Jayyousi A, Al Suwaidi J, Crystal RG, Abi Khalil C and Atkin SL: Association of vitamin D3 and its metabolites in subjects with and without type 2 diabetes and their relationship to diabetes complications. Ther Adv Chronic Dis 11: $2040622320924159,2020$.

13. Deckers JG, Schellevis FG and Fleming DM: WHO diagnostic criteria as a validation tool for the diagnosis of diabetes mellitus: A study in five European countries. Eur J Gen Pract 12: 108-113, 2006

14. Carlson RV, Boyd KM and Webb DJ: The revision of the Declaration of Helsinki: Past, present and future. Br J Clin Pharmacol 57: 695-713, 2004.

15. Dakroury Y, Butler AE, Dargham SR, Latif A, Robay A Crystal RG and Atkin SL: Association of differing qatari genotypes with Vitamin D metabolites. Int J Endocrinol 2020 : $7831590,2020$.

16. Young MJ, Breddy JL, Veves A and Boulton AJ: The prediction of diabetic neuropathic foot ulceration using vibration perception thresholds. A prospective study. Diabetes Care 17: 557-560, 1994
17. Hansson GK: Inflammation, atherosclerosis, and coronary artery disease. N Engl J Med 352: 1685-1695, 2005.

18. Campia U, Gerhard-Herman M, Piazza G and Goldhaber SZ: Peripheral artery disease: Past, present, and future. Am J Med 132: 1133-1141, 2019.

19. Hu X, De Silva TM, Chen J and Faraci FM: Cerebral vascular disease and neurovascular injury in ischemic stroke. Circ Res 120: 449-471, 2017.

20. Ahmed LHM, Butler AE, Dargham SR, Latif A, Robay A, Chidiac OM, Jayyousi A, Al Suwaidi J, Crystal RG, Atkin SL and Abi Khalil C: Association of vitamin $\mathrm{D}_{2}$ and $\mathrm{D}_{3}$ with type 2 diabetes complications. BMC Endoc Disord 20: 65, 2020.

21. Shieh A, Chun RF, Ma C, Witzel S, Meyer B, Rafison B, Swinkels L, Huijs T, Pepkowitz S, Holmquist B, et al: Effects of high-dose Vitamin D2 versus D3 on total and Free 25-Hydroxyvitamin D and markers of calcium balance. J Clin Endocrinol Metab 101: 3070-3078, 2016.

22. de Boer IH, Tinker LF, Connelly S, Curb JD, Howard BV, Kestenbaum B, Larson JC, Manson JE, Margolis KL, Siscovick DS, et al: Calcium plus vitamin D supplementation and the risk of incident diabetes in the Women's Health Initiative. Diabetes Care 31: 701-707, 2008.

23. Luo BA, Gao F and Qin LL: The association between Vitamin D deficiency and diabetic retinopathy in type 2 diabetes: A meta-analysis of observational studies. Nutrients 9: 307, 2017.

24. Issa CM: Vitamin D and type 2 diabetes mellitus. Adv Exp Med Biol 996: 193-205, 2017.

25. Liu E, Meigs JB, Pittas AG, Economos CD, McKeown NM, Booth SL and Jacques PF: Predicted 25-hydroxyvitamin D score and incident type 2 diabetes in the Framingham Offspring Study. Am J Clin Nutr 91: 1627-1633, 2010.

26. Gagnon C, Lu ZX, Magliano DJ, Dunstan DW, Shaw JE, Zimmet PZ, Sikaris K, Grantham N, Ebeling PR and Daly RM: Serum 25-hydroxyvitamin D, calcium intake, and risk of type 2 diabetes after 5 years: Results from a national, population-based prospective study (the Australian Diabetes, Obesity and Lifestyle study). Diabetes Care 34: 1133-1138, 2011.

27. Lim S, Kim MJ, Choi SH, Shin CS, Park KS, Jang HC, Billings LK and Meigs JB: Association of vitamin D deficiency with incidence of type 2 diabetes in high-risk Asian subjects. Am J Clin Nutr 97: 524-530, 2013.

28. Devaraj S, Jialal G, Cook T, Siegel D and Jialal I: Low vitamin D levels in Northern American adults with the metabolic syndrome. Horm Metab Res 43: 72-74, 2011.

29. Jorde R, Sneve M, Emaus N, Figenschau Y and Grimnes G: Cross-sectional and longitudinal relation between serum 25-hydroxyvitamin D and body mass index: The Tromso study. Eur J Nutr 49: 401-407, 2010.

30. Mitri J, Dawson-Hughes B, Hu FB and Pittas AG: Effects of vitamin $\mathrm{D}$ and calcium supplementation on pancreatic beta cell function, insulin sensitivity, and glycemia in adults at high risk of diabetes: The Calcium and Vitamin D for diabetes mellitus (CaDDM) randomized controlled trial. Am J Clin Nutr 94: 486-494, 2011

31. Dunlop TW, Vaisanen S, Frank C, Molnar F, Sinkkonen L and Carlberg $\mathrm{C}$ : The human peroxisome proliferator-activated receptor delta gene is a primary target of 1alpha,25-dihydroxyvitamin D3 and its nuclear receptor. J Mol Biol 349: 248-260, 2005.

32. Angellotti E, D'Alessio D, Dawson-Hughes B, Nelson J, Cohen RM, Gastaldelli A and Pittas AG: Vitamin D supplementation in patients with type 2 diabetes: The Vitamin D for established type 2 diabetes (DDM2) study. J Endocr Soc 2: 310-321, 2018

33. Mirhosseini N, Vatanparast H, Mazidi M and Kimball SM: The effect of improved serum 25-Hydroxyvitamin D status on glycemic control in diabetic patients: A Meta-analysis. J Clin Endocrinol Metab 102: 3097-3110, 2017.

34. Wu C, Qiu S, Zhu X and Li L: Vitamin D supplementation and glycemic control in type 2 diabetes patients: A systematic review and meta-analysis. Metabolism 73: 67-76, 2017.

35. Krul-Poel YH, Ter Wee MM, Lips P and Simsek S: Management of Endocrine Disease: The effect of vitamin D supplementation on glycaemic control in patients with type 2 diabetes mellitus: A systematic review and meta-analysis. Eur J Endocrinol 176: R1-R14, 2017.

36. Wehmeier K, Onstead-Haas LM, Wong NC, Mooradian AD and Haas MJ: Pro-inflammatory signaling by 24,25-dihydroxyvitamin D3 in HepG2 cells. J Mol Endocrinol 57: 87-96, 2016.

This work is licensed under a Creative Commons Attribution-NonCommercial-NoDerivatives 4.0 International (CC BY-NC-ND 4.0) License. 